\title{
Surveillance for Retinopathy of Prematurity in Practice: Experience From One Neonatal Intensive Care Unit
}

\author{
J. F. ACHESON and W. E. SCHULENBURG \\ London
}

\begin{abstract}
Summary
We have reviewed the results of a six year surveillance programme for acute Retinopathy of Prematurity (ROP) in order to see how the yield of cases reaching clinically significant stage 3 can safely be maximised, and to assess the effectiveness of an examination technique which does not require a speculum or scleral indentation.

An overall $137(44.8 \%)$ developed some signs of ROP and $35(10.8 \%)$ reached stage 3. Seventeen of these were born at 25 weeks or less gestational age, and included four with rush-type disease.

None of those born at or over 30 weeks developed stage 3 . It is concluded that infants born at 31 weeks or more do not need to be included in a surveillance program, and this protocol will increase the yield of significant disease. In addition, cases of stage 3 which may require cryosurgery will not be missed using an atraumatic examination technique.
\end{abstract}

Improved methods in neonatal intensive care have led to an increase in the number of surviving very low birth weight babies without reducing their susceptibility to Retinopathy of Prematurity (ROP). ${ }^{1-7}$ In the 1980 s the incidence of bilateral blindness due to ROP was estimated to be 1 to 2 million leading to an annual accrual of 550 cases in the United States and 50-100 cases in the United Kingdom. ${ }^{8,9}$

Cryosurgery has been proposed as a means of inducing regression in selected cases of acute stage 3 plus ROP where retinal detachment appears imminent. ${ }^{10-12}$ Spontaneous regression of earlier stages does not normally leave clinically significant cicatricial sequelae whereas an eye which reaches stage 3 with extraretinal neovascularisation may either progress to a vitreo-retinal phase and retinal detachment before regression, or may regress with relatively insignificant local changes (Fig. 1). The North American Cryotherapy for Retinopathy of Prematurity Study Group trial (Cryo-ROP) $)^{13}$ showed that regression could be induced and blindness prevented in a significant number of cases. $21.8 \%$ of treated eyes ended with an unfavourable anatomical outcome compared to $43 \%$ of those untreated.

Although acute ROP may affect up to $50 \%$ of infants at risk, severe disease is rare and spontaneous regression without clinically significant sequelae is the commonest outcome. ${ }^{14}$ In the Cryo-ROP study ${ }^{13} 3852$ infants weighing less than $1251 \mathrm{gm}$ were examined to find $291 \quad(7.5 \%)$ with sufficiently severe disease to be entered randomly into treatment and non-treatment categories. In another

From: Neonatal Unit, Hammersmith Hospital, London Wester Ophthalmic Hospital, London.

Correspondence to: W. E. Schulenburg FRCS, FCOPhil, Western Ophthalmic Hospital, Marylebone Road, London NW1 5YE. 
ACTIVE RETINOPATHY

(retinal phase)

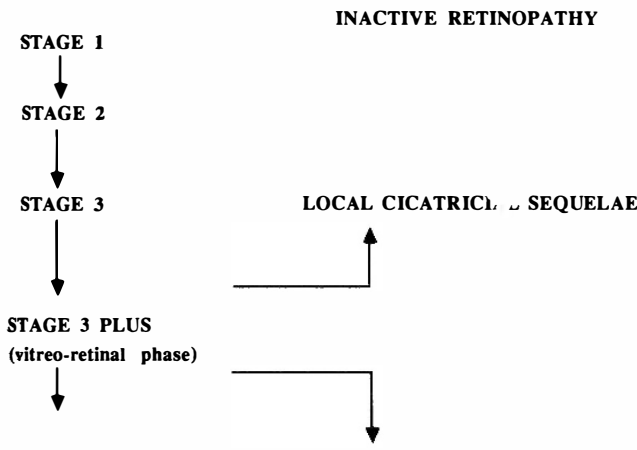

STAGE 4

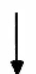

RETINAL DETACHMENT AND BLINDNESS

STAGE 5

Fig. 1. Flow chart for acute ROP indicating the clinical importance of stage 3.

community-based survey of 505 infants ${ }^{15}$ with a birth weight of less than $1701 \mathrm{gm}$ only 21 $(4 \%)$ were found to reach stage 3 disease. It is clear that examining premature babies adequately is costly in terms of time and expertise, when most are either normal or have insignificantly disturbed retinal vascular development.

Not only is ROP surveillance costly but the potential risk to the infant from the examinations must also be remembered. Possible adverse consequences of examination include bradycardia, apnoea and local ocular trauma especially when a lid speculum and scleral indentation is used. ${ }^{16-18}$

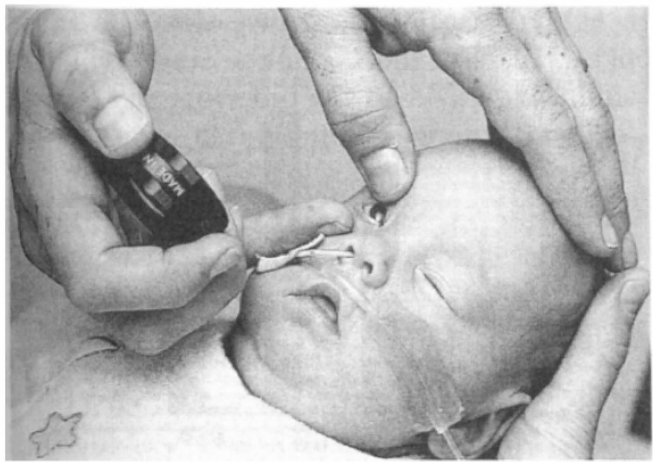

For practical purposes, the objective of surveillance may be said to be to identify eyes reaching stage 3 in time to make a decision regarding cryotherapy without causing undue morbidity.

An ROP Surveillance Programme has been in operation at the Hammersmith Hospital since $1984 .{ }^{14,19}$ We have reviewed the results in order to see how the yield of cases reaching stage 3 can safely be maximised, and to review the effectiveness of an atraumatic examination technique.

\section{Materials and Methods}

All surviving infants born between July 1983 and December 1989 at 30 weeks or less gestational age after intrauterine transfer to the Hammersmith Hospital were entered into a surveillance program for ROP.

Gestational age was determined by postmenstrual dates supplemented by pre-natal ultrasound and post-natal developmental assessment. Vitamin E was not routinely used.

Transcutaneous oxygen electrodes were used throughout the period in the neonatal unit, and intra-arterial blood pressure and oxygen tension monitoring employed during the period of assisted mechanical ventilation.

Serial ophthalmic examinations were conducted at weekly intervals from the third or fourth post-natal week whether the infants continued to require mechanical ventilation or not. Pupils were dilated with $2.5 \%$ Phenylephrine and either $0.5 \%$ Tropicamide or $0.5 \%$ Cyclopentolate drops and the fundi examined by indirect ophthalmoscopy with a

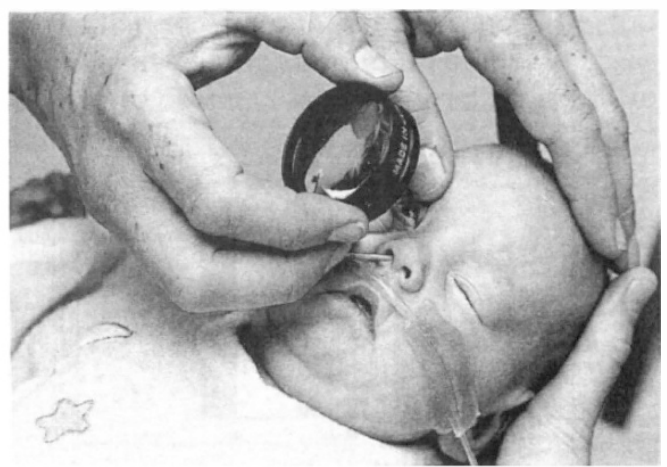

Fig. 2a \& b. Examination technique: Indirect ophthalmoscopy without use of a speculum or scleral indentation (see text). 
Table I. Breakdown of all infants examined by gestational age and maximum stage of acute ROP reached. Stage 3 cases which progressed further to stages 4 and 5 are recorded as stage 3.

\begin{tabular}{lcccrcrcr}
\hline & \multicolumn{7}{c}{ Stage reached } & \\
\cline { 2 - 7 } Gestational age & No ROP & Pre-ROP & St 1 & St 2 & St 3 & Total \\
\hline$\leqslant 25$ weeks & 6 & 1 & 4 & 7 & 17 & $(48.5 \%)$ & 35 \\
$26-27$ & 26 & 15 & 10 & 15 & 11 & $(14.2 \%)$ & 77 \\
$28-29$ & 75 & 15 & 13 & 8 & 7 & $(5.9 \%)$ & 118 \\
30 & 60 & 6 & 5 & 3 & 0 & $(0 \%)$ & 74 \\
Total & 167 & 37 & 32 & 33 & 35 & & 304 \\
\hline
\end{tabular}

+28 dioptre lens. A lid speculum, scleral identation and topical anaesthesia were not used routinely. Only those infants requiring mechanical ventilation were examined without being removed from the cot. The majority were satisfactorily examined held in the mother's or a nurse's arms with supplementary oxygen given via a face mask as required. Instead of using a speculum, the eyelids were prised apart by the ophthalmologist's left hand, the right holding the indirect ophthalmoscope lens. This method, in our experience, was less likely to provoke reflex blepharospasm and Bell's phenomenom, particularly if the light from the indirect ophthalmoscope was not too bright. In place of a scleral indenter or squint hook, adequate peripheral retinal views was normally obtained by simply waiting for the infant spontaneously to look away from the light source. (Figs $2 \mathrm{a} \&$ b)

Clinical data was recorded using the International Classifications of Retinopathy of Prematurity ${ }^{20,21}$ with the additional category Pre-ROP to describe those eyes with peripheral vascular dilation adjacent to avascular

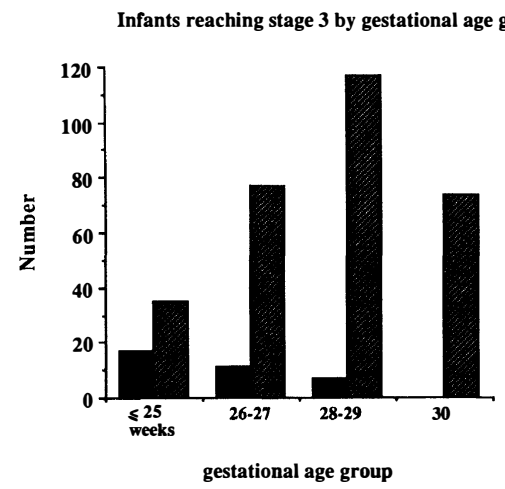

Fig. 3. retina anteriorly without evident shunt formation. Weekly examinations were continued until acute disease regression or the infant was discharged from the unit. In some cases this required a prolonged stay when the infant's general medical condition would otherwise have allowed safe transfer to a lower dependency ward in another hospital.

\section{Results}

A total of 304 infants were studied.

The breakdown of maximum stage of ROP reached for each gestational age group and the distribution of infants reaching stage 3 ROP by gestational age is shown in Table I and Figure 3.

Of the 35 infants born at or before 25 weeks gestational age, $17(48 \%)$ reached stage 3 disease and the proportion becomes successively less as the gestational age and retinal maturity at birth increase until'in the 30 week group no infants reached stage 3 .

Breaking the stages down by birth weight (Table II) shows that out of 26 infants born below $750 \mathrm{gm}, 10(37 \%)$ reached stage 3, while in the larger group of 79 infants born

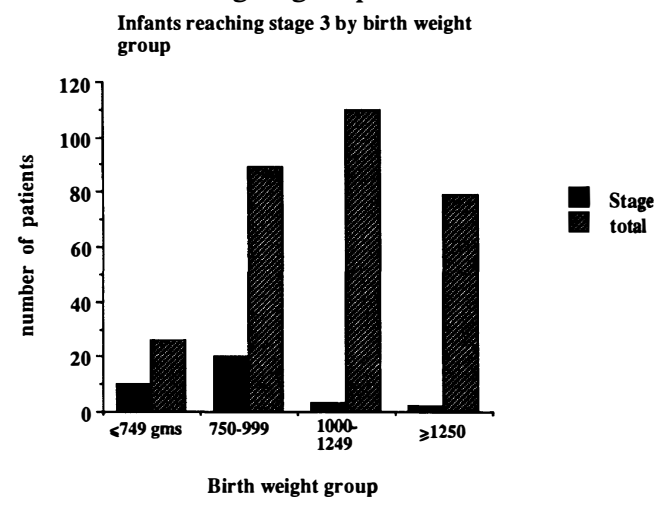

Fig. 4. 
Table II. Breakdown of all infants examined by birth weight and maximum stage of acute ROP reached. Stage 3 cases which progressed further to stages 4 and 5 are recorded as stage 3.

\begin{tabular}{|c|c|c|c|c|c|c|c|}
\hline \multirow[b]{2}{*}{ Birth weight } & \multicolumn{6}{|c|}{ Stage reached } & \multirow[b]{2}{*}{ Total } \\
\hline & No ROP & Pre-ROP & St 1 & St 2 & & St 3 & \\
\hline$\leqslant 749 \mathrm{gm}$ & 6 & 4 & 1 & 5 & 10 & $(38.4 \%)$ & 26 \\
\hline 750-999 & 24 & 4 & 15 & 16 & 20 & $(24.7 \%)$ & 89 \\
\hline $1000-1249$ & 68 & 19 & 11 & 9 & 3 & $(2.7 \%)$ & 110 \\
\hline$\geqslant 1250$ & 61 & 8 & 5 & 3 & 2 & $(3.7 \%)$ & 79 \\
\hline Totals & 159 & 45 & 32 & 33 & 35 & $(3.7 \%)$ & 304 \\
\hline
\end{tabular}

over 1250 gms only two $(2.5 \%)$ reached the same degree of acute ROP change before regression. The distribution of cases of stage 3 by birth weight is shown in Table II and Figure 4.

The numbers of infants reaching stage 3 in the group born at or before 25 weeks and the group born after 25 weeks was similar (17 and 18 infants respectively) (Figs 5a and b). The range of age of onset of stage 3 is variable and does not follow birth by a fixed period. Four cases of aggressive disease with rapid progression to stage 3 plus within seven weeks of birth (Rush-type Disease) ${ }^{19,22}$ were all in the younger group.

\section{Discussion}

The overall rate of acute ROP changes detected was $32.6 \%$ rising to $44.8 \%$ when the Pre-ROP group is included, and the rate for progression to stage' 3 was $10.8 \%$. This would rise to $15 \%$ if the surveillance programme had excluded the infants born at 30 weeks. The likelihood of progression as far as stage 3 rises with increasing prematurity (Tables I and II). No infants with a gestational age of over 29 weeks developed vision threatening stage 3 ROP in this series, and although those born at 31 weeks or more did not receive ophthalmic examination, careful follow-up by the pae-

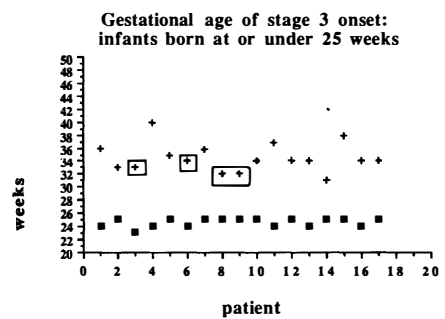

- gestational age
+ stage 3 onset

Rush-type diseas diatricians has not revealed any cases of missed severe ROP. In the East Midlands Community Study, ${ }^{15}$ only five cases of stage 3 were found amongst infants older than 28 weeks at birth out of 227 , and only one out of 170 in those born at or after 32 weeks compared to 15 out of $60(25 \%)$ born at or below 27 weeks. Other studies ${ }^{3,4,6,7}$ quote prematurity exclusively in terms of birth weight as this may be more precisely measurable than gestational age. However, the degree of retinal vascular development at birth and at the time of the various hyperoxic, hypoxic and acidotic insults of the early post natal period is an important determinant of the zone and the severity of ROP. This may reflect gestational or post-menstrual age more closely than birth weight. ${ }^{19,24}$

We have found it more practicable to define the high risk group in terms of gestational age, and suggest that, on the basis of our data infants born at 31 weeks or more have such a low risk of blindness from ROP that they may be excluded from a surveillance programme. This is not to say that advanced ROP never occurs in older infants, but that in a practical surveillance program the risk may be too small to justify the enormous number of negative extra examinations required if they were included.

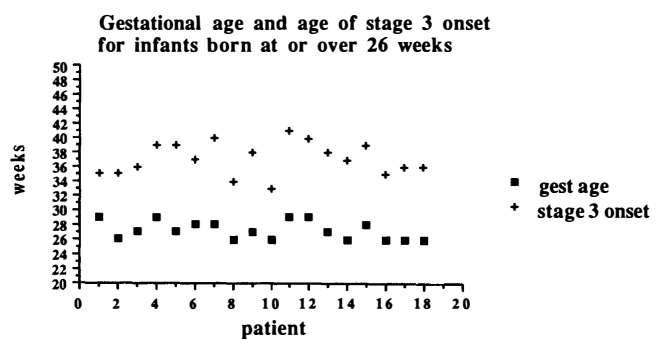

Fig. 5a \&b. 
The technique of examination by minimum intervention (no scleral indentation, no speculum) may, in our experience, lead to misinterpretations of the relatively minor physical signs which distinguish Pre-ROP from stage 1 ROP according to whether or not a demarcation line is seen. This accounts for the difference between the overall rate of $32.6 \%$ of definite ROP in our study compared to up to $49 \%$ in others. ${ }^{4,15}$

However, our figure of $10.8 \%$ reaching stage 3 is similar to or greater than the rates in comparable studies $^{3-6}$ which indicates that stage 3 cases are not being missed. It is important to note that the most important physical signs of serious plus disease (posterior vascular congestion and tortuosity) will be apparent without detailed views of the retinal periphery. Because of the risks to the infant of examination with scleral indentation, some clinicians may defer ophthalmoscopy until intensive care support is no longer required. As a result, some infants may not receive their first examination until after 38 weeks. If this practice had been applied by us the four cases of Rush-type Disease in this series would have progressed to bilateral retinal detachment before diagnosis. It is evident from figures $5 \mathrm{a}$ $\& b$ that serial examinations are required from four post-natal weeks in order to achieve the objectives stated because of the wide range of ages of onset of stage 3 .

In conclusion, this study offers evidence that ophthalmologists whose objective is to identify stage 3 eyes in time to make therapeutic decisions regarding cryotherapy without undertaking an excessive number of negative examinations can safely restrict their surveillance programme to infants born at 30 weeks gestational age or less. Secondly, an atraumatic examination technique without scleral indentation or use of a lid speculum may be appropriate for this purpose.

We are grateful to the medical, nursing and clerical staff at the Hammersmith Hospital Neonatal Unit for their support throughout this surveillance program.

Key Words: Retinopathy of Prematurity/ Screening/Surveillance.

\section{References}

${ }^{1}$ Flynn JT: Acute Proliferative Retrolental Fibroplasia: evolution of the lesion. Graefes Arch Klin Exp Ophthalmol 1975, 195: 101-11.
${ }^{2}$ Flynn JT, O'Grady GE, Herrera J, Kucher BJ, Cantolino S, Milam W: Retrolental fibroplasia. 1) Clinical observations. Arch Ophthalmol 1977, 95: 217-23.

${ }^{3}$ Keith GC and Kitchen WH: Retinopathy of Prematurity in extremely low birth weight infants Med J A ust 1984, 141: 225-7.

${ }^{4}$ Reisner SH, Amir J, Shohat M, Krikler R, Nissenkorn I, Ben-Sira I: Retinopathy of Prematurity: Incidence and Treatment. Arch Dis Child 1985, 60: 698-701.

${ }^{5}$ Clemett RS, Darlow BA, Hidajat RR, Tarr KH: Retinopathy of Prematurity: Review of five year period, examination techniques and recommendations for screening. Aust NZ Y Ophthalmol 1986, 14: 121-5.

${ }^{6}$ Darlow BA: Incidence of Retinopathy of Prematurity in New Zealand. Arch Dis Child 1988, 63: 1083-5.

${ }^{7}$ Flynn JT, Bancalari E, Bachynski BN, et al: Retinopathy of Prematurity: Diagnosis, Severity and Natural History. Ophthalmol 1987, 94: 620-9.

${ }^{8}$ Phelps DL: Vision loss due to Retinopathy of Prematurity. Lancet 1981, (i): 606.

${ }^{9}$ Schulenburg WE: Unpublished Survey 1986.

${ }^{10}$ Uemura Y: Current status of retrolental fibroplasia: report of the joint committee for the study of retrolental fibroplasia in Japan. Jpn J Ophthalmol 1977, 21: 366-78.

${ }^{11}$ Ben-Sira I, Nissenkorn I, Grunwald E, Yassur Y: Treatment of Acute Retrolental Fibroplasia by Cryopexy. Br J Ophthalmol 1980, 64: 758-62.

${ }^{12}$ Mousel DK and Hoyt CS: Cryotherapy for Retinopathy of Prematurity. Ophthalmol 1980, 87: 1121-7.

${ }^{13}$ Cryotherapy for Retinopathy of Prematurity Study Group Multicentre Trial of Cryotherapy for Retinopathy of Prematurity; Preliminary Results. Arch Ophthalmol 1988, 106: 471-9.

${ }^{14}$ Schulenburg WE, Prendiville A, Ohri R: Natural history of retinopathy of prematurity. $\mathrm{Br} \mathrm{J} \mathrm{Oph}$ thalmol 1987; 71: 837-43.

${ }^{15} \mathrm{Ng}$ YK, Shaw DE, Fielder AR, Levene MI: Epidemiology of Retinopathy of Prematurity. Lancet 1988, (ii): $1235-8$.

${ }^{16}$ Standard KP, Mushin AS, Gamsu HR: Screening for Retinopathy of Prematurity in a regional neonatal Intensive Care Unit. Eye 1989, 3: 371-8.

${ }^{17}$ Editorial Screening: the need for a balance. Eye 1989, 3: vii.

${ }^{18}$ Clarke WN, Hodges E, Noel LP, Roberts D, Coneys M: The oculocardiac reflex during ophthalmoscopy in premature infants. Am J Ophthalmol 1985; 99: 649-51.

${ }^{19}$ Prendiville A and Schulenburg WE: Clinical factors associated with Retinopathy of Prematurity. Arch Dis Child 1988, 63: 522-7.

${ }^{20}$ The International Committee for the Classification for Retinopathy of Prematurity. An International Classification of Retinopathy of Prematurity. $\mathrm{BrJ}$ Ophthalmol 1984, 68: 690-7.

${ }^{21}$ The International Committee for the Classification of the Late Stages of Retinopathy of Prematurity. An International Classification of Retinopathy of Prematurity: (ii) The Classification of Retinal 
Detachment. Arch Ophthalmol 1987, 105: 906-12.

${ }^{22}$ Nissenkorn I, Kremer I, Gilad E, Cohen S, Ben-Sira I: Rush-type Retinopathy of Prematurity: report of three cases. Br J Ophthalmol 1987, 71: 559-62.

${ }^{23}$ McPherson AR, Hittner HM, Lemos R: Retinal detachment in young premature infants with active Retrolental Fibroplasia: report on two new cases. Ophthalmology 1982, 89: 1160-9.

${ }^{24} \mathrm{Ng}$ YK, Fielder AR, Levene MI: Retinopathy of Prematurity in the United Kingdom. Eye 1987, 1: 386-90. 